\title{
Reflexión ante la vacuna de la COVID-19
}

\section{Reflection on the COVID-19 vaccine}

W s una evidencia histórica que el uso de las vacunas ha sido polémico desde que, en 1796, Edward Jenner preconizara la vacunación masiva contra la viruela, enfermedad que estaba diezmando a la población de aquellos tiempos, argumentando los críticos de esta medida preventiva muy distintos puntos de vista en el orden científico, sanitario, político e incluso religioso. $Y$ es que, al repelús ante las escoriaciones cutáneas necesarias para la transmisión del pus de otra persona previamente infectada de viruela bovina, se unía la creencia pseudocientífica de sus efectos malévolos, aludiendo al hecho de que lo que se inoculaba era "un producto de descomposición orgánica" y/o la inmoralidad religiosa que suponía "la transmisión de un producto de origen animal" a los vacunados, manifestaciones que fueron esgrimidas con mayor beligerancia cuando los gobiernos comenzaron a establecer la obligatoriedad de la vacuna, arguyendo sus detractores que dicha medida iba en contra de la libertad personal.

Pero que en el siglo XVIII se tuvieran estas ideas, podría estar dentro de la inculta normalidad de aquellos tiempos, en los que solo los más pudientes tenían la suerte de aprender a leer y escribir y los aún más poderosos podían llegar a adquirir algún conocimiento de prestigio; sin embargo, en este sentido, parece que nada haya cambiado 0 , aún peor, el cambio haya sido para empeorar las falsas creencias en cuanto a las vacunas, pues ya no son parlanchines de elixires quienes arremeten contra su uso, sino que son muchos los titulados universitarios precursores de la no-vacunación aunque, a mi modesto entender, esta actitud sea tan pseudocientífica como la de aquellos iletrados de hace más de doscientos años.

No se ha ideado aún ninguna manera más efectiva y positiva de luchar contra las epidemias que el empleo de las vacunas $y$, para demostrarlo, recordaremos algunos hechos verdaderamente históricos.

Fue en 1796 cuando el pequeño de tan solo 8 añitos de edad, James Phipps, fue inoculado por el investigador, médico rural y poeta Edward Jener, con exudado procedente de las pústulas de viruela de una ordeñadora de vacas, experimento que daría origen a las "vacunas" y que abría una era importantísima en la prevención de las enfermedades, pues con esta medida, se comenzó la lucha contra una enfermedad, ya conocida en el imperio faraónico, de elevada tasa de mortalidad (alrededor de un $30 \%$ ), especialmente elevadas en bebés, que a los supervivientes dejaba cicatrices por todo el cuerpo y, en algunos casos, ceguera (Hays, 2005; Henderson, 2011).

La viruela, de etiología desconocida, se propagaba por brotes periódicos, calculándose que llegó a producir en la Europa del siglo XVIII unas 400.000 muertes cada año y estimándose que tan solo en la mitad del siglo XX, fuera causa de hasta 300 millones de muertes, llegando a los 500 millones en los últimos cien años de su existencia, cantidad nada desdeñable si tenemos en cuenta que en 1967, apenas una década antes de su último registro, se reconocieron 15 millones de casos (Henderson, 2010).

Los programas de vacunación masiva llevados a cabo por la OMS a propuesta de la Unión Soviética desde 1967, han conseguido que a finales de 1980 se declarara oficialmente la erradicación de esta enfermedad, que junto a la peste bovina son las dos únicas enfermedades que se han logrado erradicar hasta hoy (Guidotti, 2015; Roossinck, 2016).

Por su parte, la difteria, a principios de siglo era la décima causa de muerte en el mundo, estimándose 1 millón de casos de difteria al año que producían entre 50.000-60.000 muertes anuales. En los Estados Unidos produjo 206.000 casos en 1921, con un resultado de 15.520 muertes (una proporción de un $7.5 \%$ entre casos y muertes). Tras la puesta en marcha de la vacunación antidiftérica en la década de los años veinte, se consiguió que entre los años 2004 y 2008, no se haya producido ni un solo caso en aquel país, aunque la enfermedad sigue presente a nivel mundial, habiéndose informado en 2007 de 4.190 casos de difteria en todo el mundo que, aunque el número pueda ser mayor e indica que aún no se ha erradicado, no deja de ser un esperanzador resultado de la vacuna (Asociación de Médicos de Sanidad Exterior, 2020).

Abundando en la historia de las vacunas, citaremos 
a la poliomielitis, enfermedad con frecuentes y terribles consecuencias paralizantes que, a veces, producen la muerte a quienes la padecen y que en la década entre 1940 y 1950, paralizó y mató a miles de niños.

El uso en 1954 de la vacuna anti poliomielítica inyectable, ideada por Jonás Edward Salk, ya comenzó a controlar esta horrible enfermedad, control que aún fue mejorado con la vacuna oral creada por Albert Bruce Sabin, cuyo uso fue autorizado en 1964. Las campañas masivas de vacunación llevada a cabo, han conseguido que en 2002 la OMS declarara a la Región Europea, constituida por cincuenta y un países y 850 millones de habitantes, libre de la poliomielitis, siendo el último de los casos registrados el de Turquía en noviembre de 1998 (García-Sánchez et al., 2015).

Y podríamos continuar, citando los indudables beneficios de las vacunas contra otras enfermedades, como la tosferina, el tétanos, la parotiditis, el sarampión, la varicela, la rubéola, la gripe estacional, la enfermedad neumocócica, el rotavirus o las hepatitis $A$ y $B$, pero no es el objetivo de este editorial.

Es indudable, por tanto, admitir el magnífico rol llevado a cabo por las distintas vacunas, sin embargo, a pesar de que todas ellas son seguras, no están exentas de riesgos. Cada vacuna, cuyo uso se aprueba por las oficinas competentes (FADA, en USA, o Agencia Europea del Medicamento, en Europa), ha sido previamente sometidas a pruebas rigurosas a través de las diferentes fases de los ensayos clínicos, continuando su evaluación regular incluso cuando ya está comercializada; en estas evaluaciones, los investigadores continúan analizando la información procedente de diferentes fuentes en busca de indicios de algún efecto adverso o reacción imprevista atribuible a cualquier aspecto relacionado con la vacuna.

No obstante, y aun admitiendo esos posibles riesgos, elegir la inmunización natural, es decir, esperar a padecer la enfermedad para que el cuerpo produzca sus defensas contra ella y nos inmunice, opción preconizada por los gruposantivacunas, hemos demostrarnuestro desacuerdo, pues es mayor el riesgo al que se exponen las personas que optan por ese tipo de inmunización que el que pueda producir una vacuna; por ejemplo, no es comparable la fiebre más o menos alta, el dolor de cabeza y el malestar general, que como efecto adverso pueda producir una vacuna contra la poliomielitis, que las parálisis que puede producir la propia enfermedad, debiendo también tenerse en cuenta que si bien es verdad la excepcionalidad de una muerte debido a una vacuna, no son excepcionales los casos de muertes en los no vacunados.
Ayer, sin ir más lejos, corría en las redes sociales un vídeo donde un ciudadano, evidentemente anti vacunas, recalcaba que existen dos acuerdos por los que nadie podrá ser obligado a ser vacunado, el acuerdo de Núremberg, de 1947 y el de Bioética de 2005, coincidiendo ambos en que "nadie puede obligarte a seguir un tratamiento ni a meter nada en tu cuerpo sin tu consentimiento. Y el de 2005 es todavía más explícito, pues dice que sin tu consentimiento y sin perjuicio para la persona que se niega" (sic), explicando que no se podrá impedir el acceso al trabajo, colegio o cualquier otro lugar a las personas que no deseen vacunarse.

Sin entrar a analizar lo dicho en los citados acuerdos, en España existen bases legales para decretar obligatoria la vacuna anti Covid, como cualquier otra en casos especiales, en atención a lo dispuesto en las vigentes Ley de 25 de noviembre de 1944, de Bases de Sanidad Nacional, y Ley Orgánica 3/1986, de 14 de abril, de Medidas Especiales en Materia de Salud Pública, si bien son muchos los juristas que aconsejan la adopción de medidas que favorezcan la vacunación voluntaria, ya que la vía impositiva implica evidentes riesgos de que el efecto sea contrario al propuesto.

Yo, tristemente contrariado porque algunos compañeros sanitarios se han sumado a ese carro anti vacuna, espero ilusionado la tan anunciada llegada de esas vacunas anti Covid y deseo fervientemente ser considerado grupo de riesgo - me da igual si como sanitario o como anciano - para que se me vacune cuanto antes, pues, como dijera el filósofo cordobés Lucio Anneo Séneca, "Cuando se está en medio de las adversidades, ya es tarde para ser cauto".

\section{Referencias bibliográficas}

Asociación de Médicos de Sanidad Exterior. (2020). Recuperado de https://www.amse.es/informacionepidemiologica/79-difteria-epidemiologia-ysituacion-mundial/. (Consultado el 04/12/2020)

García-Sánchez, J.E., García-Sánchez, E., GarcíaMerino, E., \& Fresnadillo-Martínez, M.J. (2015). La 
polio, el largo camino hacia el final de la partida. Enfermedades Infecciosas y Microbiología Clínica, 33(10), e69-e78. doi: 10.1016/j. eimc.2014.10.005

Guidotti, T.L. (2015). Health and Sustainability: An Introduction. Oxford, EUA: Oxford University Press. doi:10.1093/acprof:oso/9780199325337.001.0001

Hays, J.N. (2005). Epidemics and pandemics: their impacts on human history. California, EUA: ABC-Clio. Recuperado de: https://books.google.es/ books?id=BG72DwAAQBAJ\&hl=es.

Henderson, D.A. (2010). Smallpox: The Death of a Disease: The Inside Story of Eradicating a Worldwide Killer. American Journal of Epidemiology, 171(3), 384-385.

Henderson, D.A. (2011). The eradication of smallpox-an overview of the past, present, and future. Vaccine, 29(Suppl 4), D7-9. doi: 10.1016/j. vaccine.2011.06.080.

Roossinck, M.J. (2016). Virus: An Illustrated Guide to 101 Incredible Microbes. Princeton, EUA: Princeton University Press.

\section{Miguel Muñoz-Cruzado y Barba}

Presidente de la Asociación Española de Comunicación Sanitaria (AECS)

モmmunozcb@gmail.com 